\title{
Research on the Nationalization of Opera Aria and Singing
}

\author{
Hui Xu and Qi Chen \\ College of Music ,Jiangxi University of Technology
}

\section{Keyword: Nationalization of Chinese Opera Aria}

\begin{abstract}
Opera, since its born in 1920s, Chinese opera became one monobasic of numerous art form in the performing arts of China. Until now, the Chinese opera has developed for more than 80 years and in its creation path, it has formed its own unique artistic style, that it not only taken the characteristics of opera, but also and more importantly, it has absorbed the essence of many Chinese art which attained the opera with Chinese characteristics. Therefore, it is necessary to study on "nationalization" for research of Chinese opera. Research of this topic will mainly get on through collecting and analyzing studies of nationalization of some works' aria and singing, so the work itself, information of personal feelings of creators and artist, and related music criticism will be the main object. As the theoretical basis of writing, western opera, drama, and the national vocal music will also be important parts of this study.
\end{abstract}

\section{Introduction}

The art of opera has a nearly 400-year development in the West, while it came into China just for about 80 years. During the period from 1920s to 1960s, by learning from the form art of opera and combining it with aesthetic habits of our nation, Chinese artists successfully created group of national opera represented by White-Haired Girl, Honghu Red Guards and Sister Jiang in a developing line. This is a kind of national opera which use the folk music as the material and pay equal attention on singing, reading, doing and dancing, which is deeply loved by Chinese masses. After the Reform and Opening up, with frequent cultural exchange with foreign countries, the Chinese people's aesthetic taste gradually diversified, and the Chinese opera has also begun to explore new forms.

The meaning of nationalization of Chinese opera is profound. As one part of public art, opera at the same has its nationalism. The Chinese culture has a history which can approve its advancement that is accepted by generations. It has an impeccable excellence and is invincible form, example and classic. To insist on nationalization in art creation definitely does not mean to be conservative or inflexible, but to untiringly pursue the advanced culture. Some art works which reflect polarizing claims or awareness actually cannot pick their bosom friends from different viewers to declare an only dialogue with them or only display the tail feathers in front of them or to show the restrained beauty. When nationalization and internationalization become contradictory influential elements for public art, it is more or less hard to clarify the position and then to show the idea in the form. For most of the successful arts, they all pay attention to eternal beauty and need to have characteristics of speed-up and forward-looking. The characteristics of the public art like taking public aesthetic needs and levels as the priority principle, taking care of most of the viewers and valuing the average aesthetic level decide the unswerving moderate position of it. As we say, insisting on nationalization for public art is mainly to insist on a national spirit which is marvelous. Including conception of 
Confucianism and Taoism, the spirit has different customs and perceptions of 56 nations in China, featured local culture and connotation, and also rich national ideals. We shall steadily emphasize on that the ideal status of Chinese national arts in present should be to serve for most of reviewers. As a member of the public art, opera at the same time has the spirit of nationalization, so that only if the artist stick on Chinese marvelous national culture, continuously dig the profound cultural treasures contained within history of hundreds years' development of each nations, combine Chinese humanity spirit and aesthetic habits, and implant it into Chinese development of its own, can they create imperishable music. This fully proves the important meaning of nationalization for opera. Moreover, this is the meaning for the author to research on the nationalization of Chinese opera.

The significant meaning of nationalization of Chinese opera and the important position of aria for it illustrate from a wide point of view that research on Chinese opera aria and nationalization has an important historical meaning and future responsibility. From the view of realistic meaning, research on Chinese opera aria and nationalization is helpful for us to card history, sum up experience, and hold the direction of Chinese opera development in an integral way; and also conductive to provide some fertilizer for contemporary opera creators and singers which can make them create out more and better opera works holding Chinese characteristics by referencing experiences from the forefathers and carrying forward with traditions of nationalization.

Until now, Chinese opera has got help and care from many artists. Since the creation of Sparrow and Child by Li Jinhui in 1920 which marked the beginning of searching path for Chinese opera, it has had more than 80 years' history. The artists began the argument about the path of opera nationalization since $1950 \mathrm{~s}$, and more creators throw themselves into the array of theory creation, and this provides a good space for theory building of opera and also a good academic atmosphere for creators to communicate and sum up experiences timely and efficiently, what is more, it accumulates valuable theory resources to understand and study on Chinese opera.

\section{Development of Chinese Opera}

Opera is an important art form of music performance and a stage art mode combined by unique arts like drama, music, dancing, architecture, painting, etc. in which drama and music are the most essential and important elements of opera; because of which people always call opera "music form of drama" of "drama form of music". Opera in Europe experienced a long implicit history. In 6th century $\mathrm{BC}$, there has been dramas that performed by music singing in holiday for memorizing Bacchus in ancient Greek. For religious drama during period from 11th to 13th century or mystery drama and pastoral drama during period from 14th to 16th century, they all use singing as the performance formation and had opera elements in. However, the very beginning of opera is in Italy in the sixtieth century. And then, the Italian opera gradually got popular in everywhere of Europe and set a great influence on the development of opera arts in each countries of the world.

Chinese opera has its own developing history. It can be said that kinds of dramas formed with singing and dancing and gust presentation after Song and Yuan dynasty had "opera" characteristics but were not opera. The developing history of Chinese opera shall include 4 periods: early 1920s1944, exploration period; 1944-1949, creation period; 1949-1966, period of expansion; 1976-2000, revitalization period of Chinese national opera. There are two aspects throughout the course of development of Chinese national opera: one is the absorbing and leaning of western opera art and western outstanding culture, the other and the most important one is the continuous integration with Chinese traditional art and the specific social environment, the conversion to national tradition in 
aspects of aesthetic taste and artistic expression and the aesthetic choice and value orientation of persistent pursuit for nationalization and popularization.

In period of 1920s and 1930s, children's musical "Sparrow and Kids," "Little Painter" (composed by Li Jinhui) and music drama "Yangtze River Storm" (composed by Nie Er) are all equal emphasis on singing and dialogue. While in 1940s, works like "Song of Shanghai" (composed by Zhang Hao), "Song of the Earth" (composed by Qian Renkang), and "Qiuzi" (composed by Huang Yuan Luo) etc. all intended to explore the path of Chinese opera by learning from Western opera. However, the real sign of the forming of Chinese opera and what plays a great role in the development of it shall be the opera "White-Haired Girl" (composed by Ma Ke, Zhang Lu, Qu Wei) which had national characteristics and created after the Yan'an Forum. Then, there was the "Liu Hulan" (composed by Luo Zongxian), "Red Leaf River" (composed by Liang Hanguang.) and other operas. To distinguish them from the traditional dramas, this kind of opera is also called

After the founding of People's Republic of China, under the guidelines of party's "A Hundred Flowers", "Past Serve the Present, Foreign Thing Serve China" and other literary policy, many artists in opera has made further exploration and many attempts in aspect of opera creation. Some sought to solve problems in aspects of portraying opera characters and music theatrical and so on; some try to learn from the experience of Western opera to make music theme consistent throughout development; and some others take the "White-Haired Girl" creative path and draw extensively on a variety of ethnic musical tone not rigidly adhere to highlight the impact of a particular local tone.

After the foundation of China, opera creation and performance, whether in subject, thinking implication, aesthetic, or melody, instrumental accompaniment, adapt to the spirit of times and the needs of real-life struggle as far as possible. Because of international cultural exchanges and the free relaxed creative environment, part of the operas of this period are similar with Western ones in respect of dramatic structure and musical structure of which few seek musical integrity, habitability and dramatic; but in spiritual content and article character and other aspects of art still show the charm of Chinese culture and local characteristics. While, most of the opera works which closely contact with revolutionary tradition and the reality of ideological struggle are generally permeated with charm and style of public life art, which specifically mean to combine Western opera techniques with Chinese drama techniques in musical structures and tend to make modern drama, singing and monologue alternately show out in respect of drama structure. Although many of the works of this period had thickly or weakly and heavily or lightly the "left-leaning" phenomenon, but reality and historical existence of style, social, economic, cultural, psychological, customs and other factors, naturally become their relatively stable and complete cultural background and literary art space.

In just a few decades, Chinese opera has been considerable developed, and formed its own characteristics: firstly, to strive to adhere to the realistic principles in creative ability to intensively reflect the struggle of life of the masses; secondly, to focus on portraying music image of the main characters and strive to create a musical singing with a distinctive image and personality to make it beautiful and touching; thirdly, to seek right solutions for problem of inheriting folk music traditions and learning from Western music experience so as to create opera not only with the features of the times but also with distinctive ethnic features and a variety of styles form.

For decades, since ideals pursued by the composers are different and their unique grasp on specific theme, genre and style, practices of opera music in our country has been formed with several relatively stable operatic music structural concepts and different structure types. It mainly includes: 
Plate cavity category: using rhythm and variation principle of plate as the structural principle for opera music;

Song and Dance class: learning from folk songs and dances the techniques of singing together with saying and singing together with dancing; free music structure; lively singing form; relatively short and flexible aria.

Songs drama class: inserting into a number of songs' aria in the structural framework of drama with straight play style and the musical composition of it is purely.

As the development situation of Chinese opera has already been mentioned, we know everything about decades' experiences of Chinese opera, and correspondingly having a long-term exploration on how to sing opera. In period of researching of Chinese opera in 1930s and 1940s, the style was diversity: one kind is born out of drama and folk songs and dance and pay attention to kindness and nature in order to be easily accepted by children. This style mainly resourced from Li Jinhui's writing and research on performing, and the representative was Li Lili; the other one is singings deeply influenced by showing mode of European opera and which is to show contents of Chinese opera by Bel Canto. The representative is Zhang Quan whose major works is "Qiuzi” composed by Nie Er. She successfully made the character of Qiuzi with skillful technique, rustic sweet sound and clear and precise language. Her performance is fully reflection of the aesthetic of Western opera. As can be seen from some of the comments, "Qiuzi" at the time of exploration did not succeed, but is a useful attempt, it made a very important groundwork for the future singers in singing style exploration, and then think further about what is for people willing to accept.

In early 1940s, "Art is the mouthpiece of the times". In the inspiration of Mao Zedong's "On the Yan'an Forum Speech", the mass artists set off in full swing "Younger movement", since then Yangko opera which has wide mass and strong flavor of times stood out. Yangko opera with folk songs and folk dance as the main means of artistic expression performed the new military and civilian life in border area with novel forms and contents close to masses live. In consequence, just after its appearance, Yangko opera was immediately welcomed by the masses. A group of opera singers grew up by performing Yangko opera and gradually created its own distinctive unique national character and flexible performance skills. Since actors at that time only had piazza as the performance places and they themselves were not skilled enough to use western singing technique and also because of their unclear articulation and inaudible bass and some other reasons, thus forcing some singers explored a way adapt to China's national conditions which is "change idea of following foreign styles to following local ones". They performed opera by using folk singing method and referencing folk dance performances that at the same time got a good performance results. The representative work is "Brothers and Sisters Wasteland" and representatives are Li Bo and Wang Dahua. The successful exploration of Yangko opera indicates that nationalization is necessary in the opera singing path which means the combination of Western singing method with folk songs.

The period in 1950s and 1960s is the prosperity time of Chinese opera made many famous opera singers Such as Wang Kun, Meng Yu and so on who successfully created a number of different opera image. The works in this period made a marked breakthrough in creation. Take the success of "White-Haired Girl" as the example, it lustrates the need of nationalization for opera and that singing can not deviate from the creative intent but must reflect national characteristics. Singers at that time chose a singing path with drama - opera integrated which discarding some artificial ingredients in "Western Singing Method" that are not incompatible with the new opera "White-Haired Girl" content and style, such as foreign throat trembling voice, unclear articulation and unnatural and unclear 
sound and so on, however they preserve the abdominal breathing method which is good in "Western Singing Method". At the same time, they deeply research and study on traditional folk singing method and incorporate therein with all useful elements of traditional drama aria. This attempt was successful, which can be approved by audiences' fund of it.

From the1980s until now, singing style of Chinese opera give priority to bel canto mainly because that the education system of regular conservatory of music run mainly with bel canto which constantly be accepted by vocal music talents; after the reform and opening up, because of active foreign cultural exchanges and the introduction of a large number of foreign classical opera, large opera houses mainly rehearsal the Western opera; along with enhancement of people's appreciation level, bel canto was no longer marginalized as in the past, as a result works like "Yuanye" and "Shangshi" can at the same strike deep roots. Opera performers like Wan Shanhong and Yang Hongji in their own unique way try to explore singing method that make people feel warm in national vocal music. With bel canto as the foundation, they pay attention on detail handlings which at the same time is accepted by audience.

In recent years, opera singeing tend to be more "foreign flavor", emerging a group of young singers, such as Wei Song, Yao Hong, Cheng Yuan Ye, Huang Ying, Dai Yuqiang, Liao Changyong and so on. Most of them have had practice in international stage and owned world praised which indicate that opera talents' ability in our country has been able to reach the world level, and this seems to have formed a strong contrast with our own operatic career slump. This of course is caused by several reasons, but when we feel excited and proud about the view that our singers can stand on the world stage and get loud applause from foreign audiences, shall we think about using our own language. We can illustrate the work of foreigners so incisively and vividly.

Through the above description of different periods singing style, we understood the different singing style of opera singers in different periods. In next, this paper will analyzing one by one about the works of representatives in those different period, to see how the older composer concert opera and implant folk music and drama into the opera singings.

\section{Conclusions}

"Four intonations" with different tones in our language has quite a lot of color and novel effects in respect of performing figures' speak in dramas and is good at representing various kinds of different tones, language force and intonations all of which are valuable resources for us opera operators to try to tap. Making Chinese opera move towards the world is the common goal of struggle for composers and singers, for which there are roughly three creative paths: the first one is experience group which is the work style of Chen Qigang and Tan Dun and pursues mysterious and strange feelings on techniques. Their works enjoy praise in the international community as well and has gotten a lot of compliment. The second path is to inject national folk art into the works of their own in a more subtle learning method and on the basis of creative traditions of the national opera. Some of the works as "Zhang Sai", "Cry into the Air" and "Wushan Goddess" have made great achievements in the country and had raised a thousand ripples in the comment community. The third, like the born of "Wilderness", is to make bold innovation in techniques and with national art as the basis, which too got praise from internal and external audiences. All of these three styles are necessary for us because they fulfill different audience groups and all contribute to the development of Chinese opera career. 


\section{References}

[1] Guan Lin, "Ethnic Style of Vocal Arts”, Culture and Arts Publisher, August 1984.

[2] Ju Qihong, "Outline of Opera Aesthetics", Anhui Literature and Art Publishing House, March 2003.

[3] "Discussion Collection on New Opera", Chinese Drama Press, 1958.

[4] "Selected Songs of Chinese Opera”, People's Music Publishing House, May 1992.

[5] "Sister Jiang", internal information of Shanghai opera reference room.

[6] "Research on Opera Arts" sponsored by the Shanghai Opera House, 1981-2004.

[7] Ju Qihong, "Music Drama, I am Crazy on You", hanghai Education Press, first edition, October 2002.

[8] "Dictionary of Chinese Music", People's Music Publishing House, 1985.

[9] "National Press Index", opera section 1955-1998.

[10] Liang Maochun, “Chinese Contemporary Music 1949-1989”, Beijing Broadcasting Institute Publisher, first edition, 1993. 